\title{
PREVALENCIA DE ANTICORPOS PARA CHLAMYDIA TRACHOMATIS EM GRUPOS POPULACIONAIS DO BRASIL, INGLATERRA E PORTUGAL (1)
}

\author{
Marluísa de Oliveira Guimarảes ISHAK (2), Gilanfan MUMTAZ (3), Ricardo ISHAK (2) \& Geoff RIDGWAY (3)
}

\author{
R E S U M O
}

A prevalência de anticorpos IgG, grupo-especifico para Chlamydia, em populações do Brasil, Inglaterra e Portugal foi determinada através do teste de imunofluorescência indireta, tendo-se como antígeno a cepa $\mathrm{SA}_{2}(\mathrm{f})$. Foram considerados positivos os soros com títulos de $\mathrm{IgG} \geqslant 1: 32$.

Dentre as populaçōes brasileiras, a prevalência de anticorpos para Chlamydia foi maior em Serra Norte $(76,2 \%, p<0,01)$ do que nas das populaçōes de Belém $(53,6 \%)$ e dos Îndios Xicrins $(51,3 \%)$.

Entre os pacientes do Departamento de Medicina Genito-Urinária do University College Hospital (UCH) e do quadro do mesmo Hospital, a prevalência de anticorpos anti-Chlamydia foi de $62 \%$ e $53,1 \%$, respectivamente.

Anticorpos anti-Chlamydia foram detectados em 54\% e $66 \%$ na Inglaterra e em $56 \%$ e $68 \%$ em Portugal, nas pacientes do sexo feminino que frequentavam Clínicas de Pré-Natal e de Infertilidade, respectivamente,

Os resultados encontrados mostram uma alta exposição das populaçōes testadas, à Chlamydia, principalmente do grupo de baixo nível sócio-econômico de Serra Norte, Brasil. A evidência de infeç̧ão por Chlamydia é da mesma ordem, tanto no Brasil, quanto na Inglaterra e Portugal.

UNITERMOS: Soroepidemiologia; Chlamydia trachomatis.

\section{$\begin{array}{lllllllllllllllllllll} & \mathbf{N} & \mathbf{T} & \mathbf{R} & \mathbf{O} & \mathbf{D} & \mathbf{U} & \mathbf{C} & \overline{\mathbf{A}} & \mathbf{O}\end{array}$}

A Chlamydia trachomatis, agente etiológi co do tracoma, da conjuntivite de inclusāo e do linfogranuloma venéreo vem sendo, nos últimos anos, implicada na etiologia de um número crescente de infecçōes em adultos e crianças.

A infecção genital por C. trachomatis tornou-se uma das principais doenças sexualmente transmissíveis. Na Inglaterra, a Chlamydia já foi isolada de $68 \%$ de homens com uretrites não gonocócicas (UNG), e de $62 \%$ de mulheres com gonorrea' ${ }^{1}$ E conhecido também o papel da clamídia em infecçōes oculares transmitidas pelo contacto sexual e, mais recentemente, tem-se acu mulado evidências de que a C. trachomatis cau se pneumonia, doença inflamatória pélvica, perihepatite, peritonite e endocardite $2,3,8,10,12,14$.

(1) Trabalho realizado no Laboratório de Virologia do Departamento de Microbiologia do University College Hospital. Londres, Inglaterra; com suporte financeiro da CAPES - MEC.

(2) Departamento de Patologia, Centro de Ciéncias Biológicas, Universidade Federal do Pará, Brasil.

(3) Departamento de Microbiologia, University College Hospital, Londres, Inglaterra

Endereço para correspondência: Dra. Marluisa de Oliveira Guimarảes Ishak. Departamento de Patologia do Centro de Ciências Biologicas da Universidade Federal do Pará Caixa Postal 3005. CEP 66.000 -- Belém, PA. Brasil. 
ISHAK, M. de O. G.: MUMTAZ, G.; ISHAK, R. \& RIDGWAY, G. - Prevalência de anticorpos para Chlamydia trachomatis em grupos populacionais do Brasil, Inglaterra e Portugal. Rev. Inst. Med. trop. São Paulo, 30 (1): $40-44,1988$.

Apesar das infecçōes causadas por C. trachomatis serem bem definidas nos países industrializados, a freqüência destas infecçōes na maioria dos países em desenvolvimento é desconhecida. No Brasil, o tracoma foi analisado em um estudo clínico-epidemiológico mostrando áreas da região Norte em que determinadas cidades apresentavam uma prevalência de até $33 \%^{6}$. A ocorrência de $\mathbf{C}$. trachomatis em casos de UNG em pacientes do sexo masculino em nosso país mostrou uma participaçāo desta bactéria em até $51 \%$ dos pacientes examinados ${ }^{9}$.

No presente trabalho, foi determinada a pre valência de anticorpos anti-clamídia em popula çōes distintas do Brasil, Inglaterra e Portugal.

\section{MATERIAIS E MÉTODOS}

\section{a) Soros e Populaçōes Testadas:}

As amostras de soros testadas neste estudo foram obtidas de três diferentes países: Brasil, Inglaterra e Portugal, compondo nove grupos.

As amostras de soro do Brasil foram prove nientes da Regiāo Norte, e foram obtidas do ban co de soros do Instituto Evandro Chagas, FSESP. As 97 amostras de Belém incluem um grupo populacional composto de técnicos de laboratório, médicos, professores universitários, estudantes, recepcionistas e motoristas, com idades entre 20-74 anos, de ambos os sexos. Este grupo foi tomado como a população controle do Brasil.

O grupo de Serra Norte (84 amostras de soro, de ambos os sexos, com idades entre 21-69 anos) consistiu de uma população de baixo nível sócioeconômico (empregadas domésticas, motoristas, garimpeiros, lavradores e desempregados). Devemos considerar que a falta de opção de lazer nas pequenas cidades do interior, associada aos baixos níveis de educação e uso excessivo de bebidas alcoólicas leva a uma vida promíscua, com relaçöes sexuais extra-conjugais e geralmente com múltiplos parceiros(as). Este, certamente, é o caso de Serra Norte, que é atualmente o maior centro de extração de minérios do país, atraindo um grande número de imigrantes. Esta foi considerada a populaçāo promíscua do Brasil.
A populaçāo de índios Xicrins ( 76 soros, de ambos os sexos, idades entre 20-86 anos), foi con siderada como uma comunidade relativamente fechada na época da coleta, em 1974.

Os grupos da Inglaterra foram compostos de pacientes freqüentando clínicas diversas: Departamento de Medicina Genito-Urinária (GUM) (50 soros, de ambos os sexos, idades entre 16-59 anos); Clínica Pré-Natal (50 soros, sexo feminino, idades entre 17-43 anos); Clínica de Infertilidade (50 soros, sexo feminino, idades entre 24-41 anos), e membros do quadro do University College Hos pital (UCH), Londres ( 50 soros, de ambos os sexos, idades entre 17-41 anos que tiveram seu sangue coletado para exames pré-admissionais e de controle para infecçōes laboratoriais).

Os dois grupos de Portugal foram compostos de 50 mulheres freqüentando uma clínica de Pré Natal e outras 50 mulheres freqüentando uma clínica de Infertilidade, com idades entre 18-41 anos.

O sangue foi coletado por punção venosa Os soros foram separados e mantidos a $-20^{\circ} \mathrm{C}$, até o momento do uso, com exceção das amos tras do GUM, as quais foram mantidas a $+4^{\circ} \mathrm{C}$, por uma semana, período este entre a colheita e o teste.

\section{b) Métodos}

\section{b.1) Antigeno}

A cepa de $\mathbf{C}$. trachomatis usada foi a $\mathbf{S A}_{2}$ (f), uma cepa de $\mathrm{LGV}_{2}$ adaptada em cultura de tecidos (McCoy), a qual foi obtida do Laboratório de Virologia do $\mathbf{U C H}$. A $\mathbf{S A}_{2}$ (f) reage sorologicamente com todos os sorotipos conhecidos de $\mathbf{C}$. trachomatis ${ }^{7}$.

\section{b.2) Imunofluorescência Indireta de Corpúsculo de Inclusão:}

A técnica utilizada foi descrita anteriormente $^{13}$. Os soros foram diluídos em PBS e testados nas diluiçôes de 1:32 até 1:516. Após a montagem com glicerol as lâminas foram examinadas em um microscópio de imunofluorescência (Poly var, Inglaterra) para detecção de corpúsculos de inclusão.

O título foi dado pela maior diluiçâo que apresentou uma fluorescência fraca, porém defi- 
ISHAK, M de O. G.: MUMTAZ, G: ISHAK, R, \& RIDGWAY, G. - Prevalencia de anticorpos para Chlamydia trachomatis am grupes popularmnais do Brasil. Inglat.erra e Portugal. Rev. Inst. Med. trop. São Paulo, 30 (1): 40-44, 1988

nitiva. mantendo a gratulaçáo a forma das inclusoes os soros com titulos de $\operatorname{Ig}(>>1: 32$ forame somsiciaractos moitivos

$$
\text { b. } 3 \text { Metedos ristatisticos }
$$

As diferençs estatusticas significativas nas taxas de prevalencia para Chlamydia entre os vários grupos populacionais foram calculados pelo teste de chi quadrado com a correção de Yates

\section{RESUITTADOS}

A prevalência de anticorpos IgG anti-clamí dia na população brasileira, de acordo com o sexo pode ser observada na tabela 1 . Foram de tectados anticorpos em $53,6 \%(52 / 97)$ dos soros de Belém, em $76.2 \%(64.84)$ dos soros de Serra
Norte, e em $51,3 \%(39 / 76)$ dos soroa dos indios Xicrins. De acordo com o sexo, a prevalência entre as mulheres foi de $52,9 \%, 82,4 \%$ e $77,8 \%$, e entre os homens $54,3 \%, 72,0 \%$ e $27,5 \%$ nos três grupos, respectivamente. Títulos elevados de anticorpos ( $\geqslant 1: 512$ ) foram detectados em 7,2\%, $42,8 \%$ e $15,8 \%$ dos soros positivos nas respectivas populaçōes.

A prevalência de anticorpos IgG anti-clamídia, de acordo com o sexo, na população inglesa freqüentando o GUM (UCH) e membros do quadro do mesmo hospital (Tabela 1 ) foi $62 \%$ (31/50) e $53,1 \%(26 / 49)$, respectivamente. As taxas de prevalência foram $55,9 \%$ e $60 \%$ para o sexo masculino e $75 \%$ e $52,3 \%$ para o sexo feminino, respectivamente. A tabela 1 mostra os títulos de IgG $\geqslant 1: 512$ em $18 \%$ e $4,1 \%$ dos soros positivos, nas respectivas populaçōes.

TABELA 1

Prevalencia de antimorpos anti chlamydia em amostras de soro de grupos populacionais do Brasil. Inglaterra e Portugal

\begin{tabular}{|c|c|c|c|c|c|c|c|c|}
\hline \multirow{2}{*}{ Pais } & \multirow{2}{*}{$\begin{array}{l}\text { Mrigtem das } \\
\text { amostras }\end{array}$} & \multirow{2}{*}{$\begin{array}{c}\mathrm{N} \\
\text { testado }\end{array}$} & \multicolumn{3}{|c|}{ Prevalência } & \multicolumn{3}{|c|}{ Freqũência de títulos } \\
\hline & & & Total & Masculino & Feminino & $\leqslant 1: 32$ & $1: 32-1: 256$ & $\geqslant 1: 512(\%)$ \\
\hline \multirow[t]{3}{*}{ Hrasii } & Berm, PA & 97 & $53.6:+9.8 ?^{*}$ & 54,3 & 52,9 & 45 & 45 & $7(7,2)$ \\
\hline & Serrat Norte, PA & 84 & $76.2 \div \pm 9.01$ & 72,0 & 82,4 & 20 & 28 & $36(42,8)$ \\
\hline & Endios Xinns. PA & 76 & $51.31+11.21$ & 27,5 & 77,8 & 37 & 26 & $12(15,8)$ \\
\hline \multirow[t]{5}{*}{ Inglatarta } & flinire do lorenges & & & & & & & \\
\hline & thonth d? narias & 59 & $62.0\}+13.5\}$ & 55,9 & 75,0 & 19 & 22 & $9(18,0)$ \\
\hline & Guartie, 11: $\mathrm{H}$ & 49 & $53: 1,1+1 ; 3,93$ & 60,0 & 52,3 & 23 & 24 & $2(4,1)$ \\
\hline & Clinic Fré Natal & 50 & $54,01+13,71$ & $-\cdots$ & 54,0 & 23 & 23 & $4(8,0)$ \\
\hline & $\begin{array}{l}\text { Clunicia de } \\
\text { Infertilidade }\end{array}$ & 50 & $66,0( \pm 12,9)$ & - & 66,0 & 17 & 21 & $12(24,0)$ \\
\hline \multirow[t]{3}{*}{ Fortugal } & Clinica Pre Natal & 50 & $56,1)( \pm 13.7)$ & - & 56,0 & 23 & 22 & $6(12,0)$ \\
\hline & Clinica de & & & & & & & \\
\hline & Tnfertitidade & 50 & $68,04 \pm 12,9)$ & -- & 68,0 & 16 & 27 & $7(14,0)$ \\
\hline
\end{tabular}

(*) Limite de cunfianca de $95 \%$

Anticorpos anti clamidia foram detectados em $54 \%(27 / 50)$ e $66 \%(33 / 50)$ dos soros da Inglaterra e em $56 \%(28 / 50)$ e $68 \%(34 / 50)$ dos soros de Portugal, referentes às Clínicas de Pré Natal e de Infertilidade, respectivamente. Títulos elevados de $\operatorname{IgG}(\leqslant 1: 512)$ foram detectados em $8 \%$ e $24 \%$ ( $p<0,001$ ) dos soros positivos das Cunicas de Pre Natal e Infertilidade da Inglaterra, respectivamente, e em $12 \%$ e $14 \%$ dos soros positivos de Portugal, respectivamente.
A populaçāo brasileira de Serra Norte teve uma prevalência de anticorpos anti-clamídia, (título $\geqslant 1: 32)$, sensivelmente mais elevada $(76,2 \%$; $\mathrm{p}<0,01)$ que todos os outros grupos. As demais populaçōes tiveram níveis de prevalência entre $51,3 \%$ a $66 \%$, porém, estes valores não tem diferença significativa $(0,5>\mathrm{p}>0,1)$.

De maneira geral, houve um aumento gradual na prevalência de anticorpos de acordo com 
ISHAK, M. de O. G.; MUMTAZ, G.; ISHAK, R. \& RIDGWAY, G. - Prevalencia de anticorpos para Chlamydia trachomatis em grupos populacionais do Brasil, Inglaterra e Portugal. Rev. Inst. Med. trop. São Paulo, 30 (1): 40-44, 1988.

a idade, porém, esta correlação nem sempre foi observada quando os grupos foram divididos por sexo, talvez por um problema de erro de amos tragem. As diferenças na prevalência de anti corpos de acordo com o sexo, foram obtidas prin cipalmente entre os índios Xicrins e entre a populaçāo inglesa freqüentando o GUM $(\mathrm{UCH})$, Entre tanto com exceção dos Xicrins $177,8 \%$ femininos e 27,5\% masculinos; $p<0,001$ ), os outros grupos tiveram diferenças não significativas.

Títulos elevados de anticorpos $(\geqslant 1: 512)$ foram detectados em $28,4 \%$ (95/334) dos soros positivos, tendo sido a maioria encontrada dentro da população de Serra Norte $(42,8 \%)$.

\section{DISCUSSÃO}

Os resultados obtidos indicam que, de modo geral, os grupos testados apresentam uma aita exposiçāo a Chlamydia e, em particular, o de Serra Norte, Brasil.

Entre os três grupos do Brasil, a positividade de IgG anti-clamídia (títulos $\geqslant 1: 32$ ) foi mais fre qüente $(76,2 \% ; \mathrm{p}<0,01)$ em Serra Norte comparativamente a Belém e os indios Xicrins, os quais mostraram níveis semelhantes de prevalência $(53,6 \%$ e $51,3 \%$, respectivamente). Estes dois últimos índices sāo maiores que os $25 \%$ encontrados anteriormente ${ }^{7}$ entre adultos normais, assim como a prevalência de Serra Norte é superior aos $66 \%$ descritos entre pacientes que frequentam uma clínica de doenças sexualmente transmis síveis $^{7}$. Como a C. trachomatis se utiliza da via de transmissāo sexual, não é surpresa o encontro de tais niveis de prevalência. As características da população de Serra Norte favorecem a ocor rência de contatos sexuais múltiplos e ao acaso. A associação entre a soropositividade e o aumen to na freqüência de contatos sexuais já foi de monstrada anteriormente ${ }^{11}$.

A prevalência de anticorpos entre os índios Xicrins foi maior do que o esperado; entretanto, sabendo-se que o tracoma é endêmico nesta área do Estado é possível que exista outra forma de transmissão que não a sexual. Agentes como o herpes simples tipo 2 e Treponema, que possuem um padrão de transmissão sexual, são endêmi cos entre estes índios ${ }^{4}$, porém, não há correlação de transmissāo entre cônjuges, indicando outra forma de transmissāo. Os baixos níveis de higie ne mantidos por força dos hábitos culturais des te grupo, sem dúvida colaboram com a dissemi naçāo desta bactéria entre os Xicrins.

O nível de prevalència encontrado nos mem bros do quadro do $\mathrm{UCH}$, uma população contro le, é similar ao da populaçāo de Belém $(53,1 \%$ e $53,6 \%$, respectivamente), entretanto, o encon tro de $62 \%$ de prevaléncia na população do GUM, comparativamente menor do que o de Serra Norte $(76,2 \%)$, sugere uma exposiçāo à Chlamydia tão grande ou maior no Brasil do que na Inglaterra.

Os resultados encontrados entre gestantes $(54 \%)$ e mulheres inférteis $(66 \%)$ na Inglaterra é similar ao de Portugal $156 \%$ e $68 \%$, respectivamente) porém maiores que aqueles descritos an teriormente (de $46 \%$ e $48 \%$ ) por CONWAY et al..

Títulos altos de anticorpos para Chlamydia são relacionados com infecçāo recente ou infec ção contínua por esta bactéria ${ }^{5}$. A tabela 1 mos tra a freqüência de indivíduos testados com títu los $\geqslant 1: 512$ para esta bactéria. Sem dúvida, a população de Serra Norte mostra evidencias de ser a más envolvida pela infecção corroborando a possibilidade de maior transmissão por via se xual

No presente estudo. o teste de imunofluo rescência foi efetuado usando-se um antígeno imunologicamente semelhante ao sorotipo $\mathrm{LGV}_{2}$ e que reage sorologicamente com os imunotipos dos grupos B e ED, comumente associa dos com a infecçāo do trato genito-urinário em seres humanos ${ }^{15}$.

Estes teste é adequado para a triagem de um grande numero de amostras de soro por ser de metodologia simples e por detectar anticor. pos contra os sorotipos mais predominantes. Por outro lado, o mesmo não permite a distinção entre cepas que usualmente infectam o olho $\mathrm{e}$ o trato genital, ou entre as espécies de C. trachomatis e C.psittaci.

Os altos níveis de prevalência para Chlamydia no Brasil mostram a necessidade de se popularizar os métodos de diagnóstico baseados na detecção de antígeno a fim de que se possa tratar mais eficazmente a infecçāo por esta bactéria e limitar os danos e complicaçōes tais como epi 
ISHAK, M. de O. G.; MUMTAZ, G.; ISHAK, R. \& RIDGWAY, G. -- Prevaléncia de anticorpos para Chlamydia trachomatis em grupos populacionais do Brasil, Inglaterra e Portugal.

Rev. Inst. Med. trop. Sáo Paulo, 30 (1): 40-44, 1988

didimites, salpingit $\epsilon$, infertilidade e infecçōes neonatais. E necessário enfatizar que a infecçāo pela Chlamydia apesar de, com freqüência, evo luir para uma forma crônica, possui, no entanto, uma forma inicial e satisfatória de ser tratada, desde que corretamente diagnosticada.

\section{SUMMAR Y}

Prevalence of Chlamydial antibody in populations from Brazil, England and Portugal

The prevalence of group - specific antichlamydial IgG in populations from Brazil, England and Portugal was studied using the whole inclusion - indirect immunofluorescence test, and $\mathrm{SA}_{2}$ (f) as antigen. Those sera with the IgG titre $\geqslant 1: 32$, were considered to be positive.

Among the Brazilian populations, prevalen ce of chlamydial antibody was higher in Serra Norte $(76,2 \%, \mathrm{p}<0,01)$ than in Belem $(53.6 \%)$ and among Xicrins Indians $(51,3 \%)$.

In patients attending the Departament of Genito Urinary Medicine, University College Hospital and in members of the UCH staff, London, England, the prevalence of antichlamydial IgG was $62 \%$ and $53,1 \%$, respectively.

Antibody to Chlamydia was detected in $54 \%$ and $66 \%$ of the English women and in 56 and $68 \%$ of the Portuguese women attending Ante natal and Infertility Clinics, respectively.

These results show a wide exposure to Chlamydia among all the populations tested, mainly among the low socio-economic group of Serra Norte, Brazil. Evidence of chlamydial infections is of the same order in Brazil, England and Por tugal.

\section{AGRADECIMENTOS}

Os autores agradecem a Dra. ELAINE PINA, Maternidade Dr. Alfredo da Costa, Lisboa, Portugal e Dr. ALEXANDRE DA COSTA LINHARES. Instituto Evandro Chagas, FSESP, Belém, Pará, Brasil, pelo fornecimento das amostras de soro de Portugal e do Brasil, respectivamente.

\section{REFERENCIAS}

1. ALANI. M. D.: DAROUGAR. S.: BURNS, D. C. THIN R. N \& DUNN, H. - Isolation of Chlamydia trachomatis from male urethra. Brit. J. Vener. Dis., 53: 88-92, 1977.
2. Anonymous. Chlamydial infections of the eye Lancet, $z$ $857.858,1977$.

3. BEEM, M. O. \& SAXON, E. M - Respiratory tract coloni zation and a distinctive pneumonia syndrome in infants infected with Chlamydia trachomatis. New Engl. J. Med., 296: $306 \cdot 310,1977$

4. BLACK, F. L.; HIERHOLZER, W, J.; PINHEIRO, F. P.: EVANS, A. S.; WOODWALL, J. P ; OPTON, E. M.; EMMONS, J. E.; WEST. B. S.: EDSALL. G.: DOWNS, W. G. \& WALLACE, G. D. - Evidence for persistence of infec tious agents in isolated human populations. Amer. J. Epidem., $100: 230-250,1974$

5. CONWAY, D.; CAUL, E. O ; HULL, M. G. R.: GLAZENER C. M. A : HODGSON J : CLARKE, S. K. R. \& STIRRAT, G. M. - Chlamydial serology in fertile and infertile women. Lancet, 1: 191:193. 1984

6. FREITAS, C. A. - Prevalència do tracoma no Brasil. Rev bras. Malar., 28: 227, 1976

7. GRAYSTON, J. T. \& WANG, S. P. - New knowledge of chlamydial and the diseases they cause .J. infect Dis. 132: $87 \cdot 105,1975$

8. HILTON, A. L; RICHMOND, S. J.; MILNE, J. D; HIND LEY, F. \& CLARKE, S. K. R. - Chlamydia in the female genital tract. Brit. J. Vener. Dis., 50: 1-10, 1974

9. MAGALHÁES, M.; ANDRADE, M. \& VERAS, A. - Uretri tes nāo gonocócicas masculinas associadas a Chlamydia, Ureaplasma e Trichomonas. Rev. Mierobiol. (S. Paulo), 13 . $156-160,1982$.

10. MARDH, P. A. SVENSSON, L.: WESTROM. L. \& DA ROUGAR, S. - Antibodies to Chlamydia trachomatis in acute salpingitis. Brit. J. Vener. Dis., $55: 26 \cdot 29,1979$

11. MCCOMB, D. E.: NICHOLS, R. L.: SEMINE, D. Z.: EVE RARD, J.R.; ALPERT, S.: CROCKETT, V. A : ROSNER B.: ZINNER, S. H. \& MCCORMACK, W. M. - C. trachomatis in women: antibody in cervical secretions as possi ble indication of genital infection. J. infect. Dis., 139: $628.633,1979$.

12. MÜLLER SCHOOP, J.W:WANG, S. P: MUNZINGER, J.; SCHLAPFER, H. U.; KNOBLAUCH, M. \& AMMANN, R. W. -- Chlamydia trachomatis as a possible cause of peritonites and perihepatites in young women. Brit. med. J., 1: $1022-1024,1978$.

13. RICHMOND, S. J. \& CAUL, E. O. - Fluorescent antibody study in chlamydial infection. J. clin. Microbiol., 1: 345352,1975 .

14. VAN DER BEL-KAHN, J.M.; WATANAKUNOKORN, C. MENEFEE, M. G.; LONG, H. D. \& DICTER, R. - Chlamydia trachomatis endocardites. Amer. Heart J., 95: 627, 1978

15. WANG, S. P. \& GRAYSTON, J T. Human serology in Chlamydia trachomatis infection with microimmuno fluorescence. J. infect. Dis., 130: 388 -397, 1974.

Recebido para publicaçāo em 10/09/1987 